\title{
Study of Application-oriented Film and Television Art Talent Practice Platform
}

\author{
Wenhao Wang, a , Xin Huang ${ }^{2, b}$ \\ ${ }^{1}$ College of Humanities \& Sciences of Northeast Normal University, Changchun, Jilin, 130000 \\ ${ }^{2}$ Jilin Normal University, Siping, Jilin, 136000
}

Keywords: Practice Platform, Art Talent, Film and Television

\begin{abstract}
With the industrialization of education, the expansion of colleges and universities, and the expansion of art schools in various colleges and universities, it is both a happy event and a worry. The cultivation of talents in film and television drama art education in colleges and universities should not only cultivate art elites, but also cultivate professional, innovative and compound application talents, so that talents can not only adapt to the needs of the market, but also adapt to market transformation. Therefore, college film and television performing arts education needs to think about the talent training mode in terms of curriculum, art practice, employment guidance and so on.
\end{abstract}

\section{Introduction}

"Now China is already an economic power. Similarly, we have always been a cultural power, but China is not a cultural power." The report of the 18th National Congress pointed out that the current development of China's cultural industry has stood at a new historical starting point and entered a breakthrough. The new period and new stage of sexual progress will continue to be in an important period of development opportunities in the next 10 to 20 years. Film and television is the most dynamic and vital part of the cultural industry. It is developing very rapidly. The demand for applied, composite and innovative talents is increasing rapidly. The practical teaching of film and television courses has increasingly highlighted its significance.

\section{The development of cultural industry calls for the cultivation of applied talents}

Unlike the cultural undertakings that provide public welfare cultural services to the public, the cultural industry embodies the economic attributes of culture. The concept of cultural industry stems from the cultural industry proposed by the Frankfurt school leaders Adorno and Horkheimer in the Dialectics of Enlightenment (1947). Adorno and others have a negative critical attitude towards it. Later, American scholar Daniel Bell put forward the concept of "cultural industry" in "The Coming of Post-industrial Society", clearly linking cultural production with consumption and market, revealing the law of culture and market, and pointing out that culture must satisfy the market. The market is driving the development of culture. UNESCO has given a very succinct definition of the cultural industry: the cultural industry is a series of activities that produce, reproduce, store and distribute cultural goods and services in accordance with industry standards. Due to different cultural policies, regional characteristics, and degree of economic development, different countries have different formulations of cultural industries, and the industries involved are not the same, but they are consistent in the view of the cultural industry strength as the embodiment of comprehensive national strength. The prosperity of the cultural industry benefits from globalization and modern high-tech development. The global competition of cultural capital pushes the cultural industry to the forefront of social and economic development. The cultural industry in developed countries is developing particularly rapidly. The Chinese government is also paying more and more attention to the development of cultural industries. China's accession to the WTO in 2001 greatly stimulated the development of the cultural industry. In 2002, the 16th National Congress of the Communist Party of China wrote the cultural industry for the first time. In 2006, the Outline of the National Cultural Development Plan during the 11th Five-Year Plan period incorporated the 
cultural industry into the national major development strategy. At the 18th National Congress of 2013, the cultural industry became the pillar industry of the national economy and was included in the index system for building a well-off society in 2020. Accelerating the development of the cultural industry has become an important fulcrum for promoting the strategic adjustment of the economic structure and an important focus for transforming the economic development mode.

\section{The status quo of film and television performing arts talent training mode}

The imbalance of students' entry level is mainly reflected in the imbalance of cultural level and the imbalance of professional foundation. Since the art education in the national compulsory education stage only has music education and art education, and there is no film and television drama performance course, some students who come to colleges and universities for this major come from various art secondary schools or art high schools in the country, and the other part comes from ordinary high schools. The cultural quality of ordinary high school students is much higher than that of art school students, but from a professional point of view, the art comprehensive ability of art school students is stronger than that of ordinary high school students. The average high school students who do not have any performance foundations apply for the majority of the majors. They compete with the art school students for their talents and potential for performing arts during the examination. Finally, due to cultural differences, the admission rate is still Ordinary high school students are taller than art school students. In this way, it is bound to cause everything to start from the basics. There are more professional basic courses involved in the film and television performance profession, which are more demanding for the overall quality of people's voice, language and form. This is undoubtedly a pressure for ordinary high school students. In the four years of undergraduate education, it is easy to cultivate a person who has nothing at all to become an artistic leader.

The teaching practice of film and television drama performances has always been based on rehearsal repertoire. From exchange sketches, teaching fragments to rehearsal dramas, students basically use stage performance as a form of teaching and artistic practice. Whether as a student is appropriate or not, as a means of teaching, this practice must be accepted. Although the main task of the actor is the stage performance, the demand for performing arts talents in the society is not only in the profession of actors, but also in the future. Therefore, in order to broaden the employment channels, we must provide students with more forms of artistic practice opportunities.

The expansion of the enrollment scale of performing arts in colleges and universities has surpassed the speed of enrollment expansion in general universities. The number of students applying for art schools is also growing, and the number of graduates will increase. But what about the employment opportunities? CCTV has conducted a survey, and the employment rate of national performing arts graduates is less than $30 \%$. Less than $0.003 \%$ of the domestic celebrities or celebrities in the entertainment industry. In fact, it is not that the demand for performing arts talents in the society has reached saturation, but that there are too few professionals who are really qualified for the actor. Many related jobs are still in short supply. This kind of situation is objectively analyzed. There are two reasons. First, graduates have low-handed eyes, short-sighted employment, quick success, and only target individual cities and individual well-known professional theater companies. Another reason is that the employment of talents cultivated by art education in colleges and universities is too simplistic and lacks the adaptability of market transformation.

The curriculum of the film and television theatre performing arts is different from the curriculum of the liberal arts and sciences of other universities and other art majors. Some institutions arrange classes on weekends and evenings. Because of the principle of teaching students in accordance with their aptitude, the professional skills of the performance profession are often the implementation of the "small class system" teaching. As a professional skill course, the sound, the table, the shape and the table are four sections in accordance with the past practice, at least twice a week. The exchange of small items in the performance class takes a long time. If you take the exchange of two people as an example, as a college student, you should have enough time for them to digest and absorb the 
professional skills and knowledge they have learned. The space for development. And the full schedule, from the schooling unit, will undoubtedly be a challenge to the teaching cost, management, teaching software and hardware, but for students, it inhibits the space for their development, which is extremely unfavorable. Learning expansion and scientific research.

\section{Application-oriented personnel training requires strengthening practical teaching}

The complete film and television teaching should include three aspects: theoretical knowledge learning, skill training and practical application. Professional film and television art colleges have no major problems in this respect. The author's emphasis on the practice of teaching is mainly for the film and television curriculum in the second case. In the current teaching of the second and third film courses, the general teaching mode is knowledge teaching, then filming, watching movies, and filming. The content of the lecture is simple, mainly for film and television appreciation, analyzing the theme, characters, plots, meanings of film and television works, and carrying out aesthetic education, failing to achieve the purpose of film and television art literacy education. In particular, the quality class is very limited, and some even have only 20 class hours. The limitation of class time makes it impossible for teachers to complete the entire content of teaching, which can only be deleted, making the teaching of film and television a bit sloppy and fragmented. The scientific outlook on development inspires us that education must adhere to the people-oriented spirit, as well as film and television teaching. According to the feedback from students over the years, after mastering the film and television language, after knowing the classification of montage, the meaning of long shots, and understanding the various motion shots, students hope to use this knowledge to shoot and produce beautiful micro-movies or Other video works. In the era of visual flooding and the use of a smart phone in the hands of students, it is not uncommon for students to watch their favorite movies and TV shows in the classroom with their mobile phones. The beautiful PPT, the so-called classic films in the eyes of teachers, the wonderful analysis has long been called. After 90 years of college students' interest. Post-90s college students have a seemingly innate interest in digital high-tech products and the ability to get started quickly. There are a large number of their works on major video websites, and many beautiful and creative productions are not from film and television students. Hand. Under the current situation that the employment pressure of general professional talents has increased in an all-round way, a considerable number of students hope to explore and demonstrate their abilities in this way, and even find a way to find employment. They naturally hope to gain the skills to learn, get practice and show their skills from the film and television curriculum. In reality, film and television teaching lacks practical links. From a small point of view, this seems to mean closing a door for student employment; from a big point, this limits the discovery and cultivation of China's film and television talents, and naturally affects the development of China's film and television industry.

Therefore, in the film and television teaching of colleges and universities, to be based on the development of students, we should not ignore the needs of students. Compared with the specialized film and television students, Chinese language and literature, art, communication and other majors have unique competitiveness. Film and television colleges generally focus on skills training, with a high degree of specialization but insufficient cultural connotation. Comprehensive college students have in-depth study of film and television courses on the basis of relevant professional learning, and their knowledge structure has a composite character. Nowadays, people entering the field of film and television industry are getting more and more ways. In practical work, regardless of their origins, it is very common to use what they have learned in today's society. In addition, video shooting equipment is increasingly miniaturized and light-weighted, and ordinary people can also achieve image creation, which is no longer exclusive to professionals. Especially with the popularity of DV (Digital Video), college students have acquired hands-on equipment. Jia Zhangke said that Chinese movies have to enter the era of amateurs, and they are aimed at the popularity of DV. As the popularity of karaoke popularizes singing art, the development of the Internet has spawned a large number of online writers, and the popularity of DV will also spawn a group of outstanding film and television talents and film and television production. Therefore, colleges and 
universities must be guided by the needs of the cultural industry. In the teaching, we should strive to strengthen the practice teaching of film and television majors in colleges and universities. At the same time, we should pay attention to the cultivation of film and television talents' innovation ability and cultivate composite application-oriented film and television talents, thus providing more fresh blood for China's film and television industry.

\section{Conclusion}

A long-term exploration process when the practice teaching is perfect. The various methods of practical teaching of film and television courses need to be verified and perfected step by step in the specific practical work, in order to truly realize the teaching and learning, and apply what they have learned, and cultivate more and better innovative and compounded film and television talents with innovative spirit.

\section{Acknowledgements}

Fund Project: Project Name: Research on the Training Mode of Applied Talents of Film and TV Art "Study and Research Institute". Supported by Science Research Project of Jilin Provincial Department of Education

No.: JJKH20181323SK

\section{References}

[1] Li Mei. The development trend of art education and talent training mode in colleges and universities in the era of big data [J]. Art Education Research, 2016(09).

[2] Yu Wei, Wan Li. The lack of skills in high-level film and television art education in the whole media environment and its countermeasures [J]. Contemporary Education Forum, 2013 (4).

[3] Wang Yanling, Wang Yibo. The new normal of film and television art education in colleges and universities under the "Internet +" situation [J]. Film Review, 2015 (20).

[4] Zhang Lixin. Research on Undergraduate Art Application-based Innovative Education Model Based on Project Marketization in Big Data Era [J]. Art, 2015(12).

[5] Zhao Hongwei. Strengthening Practical Teaching and Training High-skilled Film and Television Technical Soldiers [J]. Modern Film Technology, 2007(3). 